\title{
Gaining Producer Buy-in for Food Safety and Security in the United States
}

\author{
Dennis J. Osborne ${ }^{1}$, Douglas C. Sanders ${ }^{2}$, Donn R. Ward ${ }^{3}$, and \\ James W. Rushing ${ }^{4}$
}

AdDitionAL INDEX wORDs. GAPs, FDA guide, farm-to-table, risk management, recall plan, train-the-trainer, NRI, integrated multi-state

SUMMARY. This paper summarizes the management framework, organizing plan, and results of a multi-state, multi-institutional partnership delivering a targeted "train-the-trainer" program addressing food chain security in the southeastern U.S. The partnership provided good agricultural practices (GAPs) and good manufacturing practices (GMPs) -based training to fresh fruit and vegetable (produce) growers and packers throughout the region. Twelve southern states cooperated in this project: Arkansas, Florida, Georgia, Kentucky, Louisiana, Mississippi, North Carolina, Oklahoma, South Carolina, Tennessee, Texas, and Virginia. This 2000-04 work was funded by National Food Safety Initiative grants. Although proposed long before events of 11 Sept. 2001, the project and its results are increasingly relevant since that time. This is because consumer expectations regarding the nation's food supply now include a new security consciousness addressed in this project.

A dDressing the Problem: Rationale. As part of the new food chain security consciousness, consumers, government agencies, and private business are increasingly concerning themselves with questions of fresh produce foodstuff contamination and are setting up "systems" of quality assurance for fresh produce. Such activity is well-placed. Fresh fruits and vegetables (produce) are subject to many forms of contamination. In particular, contamination by bacteria harmful to humans can occur readily in the chain of commerce-what is commonly referred to as "farm-totable."

A significantly sized subset of the American food supply is "manufactured" as fresh produce grown, harvested, and distributed in and from states of the southeastern U.S. If this produce is bacterially contaminated and if corrective actions after such contamination impose dollar costs, this cost may be decreased by reducing contamination potential of fresh pro-

\footnotetext{
${ }^{1}$ Wake County Public School System, N.C.

${ }^{2}$ Deceased; formerly Department of Horticultural Science, NC State University, Raleigh, NC 27695 7609.

${ }^{3}$ Department of Food Science, NC State University, Raleigh, NC 27695-7609.

${ }^{4}$ Clemson University, Coastal Research and Education Center, 2700 Savannah Highway, Charleston, SC 29414-5333.
}

duce from the region. As an adjunct of reducing the potential for food chain contamination, increasing food chain security would also result.

Since much microbial contamination of fresh produce comes as people handle the crops, producer training directed toward preventing this contamination could be a targeted way of reducing contamination of the food chain. Engaging southern U.S. growers and packers in a new national food safety dialogue could increase food security and safety, and increase awareness of producers and consumers alike.

Addressing the problem: BACKGROUnd. Among other sources, bacteria contaminating the fresh produce food chain can come from animal droppings that fall into harvest bins, contaminated irrigation or wash water, farm workers' unwashed hands contacting foodstuff and, to an unknown extent, from deliberate acts introducing contamination to foodstuff. The problem is persistent and worldwide.

As an example, as of Feb. 2004 most cantaloupe (Cucumis melo var. reticulatus) from Mexico was embargoed from U.S. entry because of such contamination. Demonstrating the potential spread of produce-related problems, 1991 and 1993 outbreaks of salmonellosis (Salmonella) in the midwestern U.S. were linked to the handling of raw tomatoes (Lycopersicon esculentum) originating in a single packinghouse in South Carolina (Rushing, 2001).

In the U.S., is any one agency or federal program "in charge" of food chain security? Surprisingly, no. Indeed, the U.S. Food and Drug Administration (FDA) of the U.S. Department of Health and Human Services is not part of the new U.S. Department of Homeland Security (DHS). The omission of FDA from DHS's organization suggests that governmental entities may not recognize farmer/producer importance in food security or, if recognizing the importance, have not decided which agency is "in charge" of farmers and producers as regards food safety.

In contrast to regulatory/structural thinking, FDA has provided major guidance for a methodology of food chain security for the national fresh produce industry in the "Guide to Minimize Microbial Food Safety Hazards for Fresh Fruits and Vegetables" [Guide (FDA, 1998)]. The Guide helps interested parties identify potential sources of microbial contamination for fresh produce and suggests how using a new system, GAPs, can reduce or eliminate that potential. GAPs for unprocessed foodstuff are analogous to hazard analysis critical control point (HACCP) systems analysis for processed foodstuff. While HACCP as a quality control/assurance system has long been in place for processed items, no similar system existed for fresh produce. Thus, FDA's publication of the Guide instituted a marked change in how fresh commodities moved in commerce.

A link between GAPs as a suggestion and actually acquainting grower/producers with such a new system was neither provided nor suggested by FDA. While addressing that missing link initially seemed to be a classic cooperative extension educational task, events of 11 Sept. 2001 showed that incorporation of food security planning could be addressed in the same programming. Thus, the authors of this paper formed a regional team to provide education and training to create the link. The team decided to incorporate food security planning and training objectives in developing educational materials used early in this project (Osborne et al., 2001). Unfortunately, while training materials could 
be developed, the size of the target audience was unknown. This meant that a new approach to reaching unknown numbers of potential participants with an entirely new quality control system was needed.

No one knows how many grower/ producer entities are in the southeastern U.S. fresh produce system. Cooperating state departments of agriculture estimated there are thousands of fresh produce growers in each southeastern state. There are so many growers that the team decided a "multiplier" educational program was essential to bring food security information to a reasonable number of the growers given the few adult educators available for the task.

Because few educational materials addressing the relationship between food chain security, fresh produce and bacterial contamination of produce existed, the materials would have to be created. Outreach and cooperative extension programs have long helped transfer government and regulatory information to the field. In contrast, this project was designed to operate at the "farmer" level and induce farmers to adopt certain business principles not often considered as such by growers in the fresh produce industry.

Implementing a GAPs program by considering any one specific GAP (Practice) from the Guide requires each adopter to develop specific strategies for that Practice as it applies to his /her business. Applying GAPs analysis is analogous to using systems thinking in HACCP and HACCP-like programs. GAPs differ from HACCP in recognizing that fresh produce rarely has critical control points as occur in process operations. Instead, critical production "activity areas" occur in crop production and any or all of the GAPs may apply to one activity group, such as planting, harvest, and packing.

FOOD SECURITY NOT ONLY MAKES SENSE, IT MAKeS PROFITS. People act from a hierarchy of needs (Maslow, 1943). In so acting, people often adopt practices yielding results they find pleasurable or desirable or profitable. Because most people involved in southeastern U.S. fresh fruit and vegetable production engage in the activity for profit, it seemed a training program showing that food security could be profitable would be more favorably viewed than would a program about regulations.
Two behavioral constraints were included as the project began to consider program elements: most small producer entities are fiercely independent and deficient in cash resources. This suggested that a program showing how to use existing resources to reduce risk and liability while improving market position would be an approach attractive to the target audience. The team had to depart from traditional cooperative extension producer programming to adopt the language of business and the motivational points of business team builders. Food security was emphasized as a team effort, in contrast to traditional programming directed to improving single entity productivity. Further, because the southern fresh produce system is multicultural, we had to create a multicultural training program.

Conceptually the approach could be called "multicultural training for global business" and is a departure from traditional cooperative extension programming. A train-the-trainer program delivery system was employed because not only are such programs team efforts, such programs leverage people resources.

The term "train-the-trainer" often is used, but seldom defined. In this project train-the-trainer meant providing specialized information and educational programming to a selected cohort of people noted for their ability to effectively deliver training programs based on that specialized information. The trainers in the cohort become areaspecialized information resources supporting those whom they have trained and the trainees later become trainers in local townships and rural areas.

Train-the-trainer is thus a training system that uses an effort multiplier approach, following the adage of "each one teaches another." Because later adopters often follow practices of first adopters, the leveraging of resources in such a system can be logarithmic rather than geometric, as many later adopters learn from one early adopter. Transferring a quality control framework to the farm level required a new curriculum design. The concepts incorporated in curriculum design for the trainer cohorts are outlined next.

Cross-cultural training FOR GLOBAL BUSINESS: GAINING BUY-IN FOR FOOD SECURITY AT THE PRODUCER LEVEL. Many traditional cooperative extension programs implement programming by showing that proposed changes in practices will help increase productivity or increase return on investment. For instance, conservation tillage was adopted because it made business sense, not purely because it was "better for the environment." Similarly, adopting GAPs could be a grower response to the positive effect such adoption had on liability reduction and potential for increased market share. The message became one of "if you adopt GAPs you not only increase your product quality and safety, you can increase profit." The message was NOT "you have to do this because regulations say so." This project represents a conceptual shift from an agricultural producer program focus to a knowledge-based, market economy focus.

In today's knowledge economy, the focus is less on getting people into classrooms and more often is on: 1) facilitating knowledge transfer, 2) leveraging learning solutions, 3 ) embedding learning in business processes and initiatives, and 4 ) increasing overall productivity. The project focused on 1 and 3 , but overall productivity increases were inevitable if programming was successfully adopted. No measurable results as regards food security metrics could be obtained because underreporting of foodborne illness is so endemic. Available information shows that many times the number of people who know they "got sick" from contaminated food merely "felt bad" and didn't consider themselves to have been victims of a foodborne illness. Measuring a reduction in cases not known to exist is not possible. Individual knowledge gains were measured using pre- and posttests and such data are reported in a previous paper. (Osborne et al., 2005)

One can record changed behavior, particularly if employees change their behaviors. Effecting such a change requires employees to adopt, or "buy-in" to the new way of doing things. This usually happens when people believe the new way is better in some way than the old way. Facilitating acceptance, buy-in, and commitment are tasks highly influenced by cultural values, attitudes, and behaviors. This means that programming must be congruent with audience culture and language.

The southeastern U.S. fresh produce industry employs large num- 
bers of Spanish-speaking people. The program had to be congruent with their language and culture, as well as with that of the majority culture. The team thus developed materials in both Spanish and English. The majority culture materials were oriented to the scientific aspects of food security; the Hispanic culture materials explained things in terms of family food supply and security.

Thematically the materials followed Rogers' (1995) adages: 1) an audience must be able to "see" the vision of change; 2) all people will view the vision through their cultural viewpoint; 3) because of 2 above, a culturally appropriate delivery style is essential for audience buy-in (i.e., ignoring delivery imperatives may result in lack of audience commitment); 4) people elucidating the vision must be trusted by the audience; and 5 ) the audience must acquire hands-on-skills sufficient to allow them to work within the vision.

With the support of U.S. Department of Agriculture (USDA) a new food safety system has been created throughout the southeastern U.S. Among the system elements are: a grower certification arrangement whereby cooperative extension provides training using the materials from this project; industry accepts university verification of the training and certifies trained producers as "approved"; and state departments of agriculture can provide inspectors and charge for the inspections.

A "Model Recall Program for the Fresh Produce Industry" (Osborne et al., 2003) has been developed and published following the form of FDAregulated product recall procedure. A model recall program is one usable by many entities. Recall programs for food products differ from those used for manufactured products in interstate commerce. FDA regulates processed food products and a federal statute explicitly states every step to follow when a processor has to recover defective products from the chain of commerce. Fresh produce is not a manufactured product and no statutory recall process analogous to that for processed food exists for fresh produce.
This new fresh produce food safety system has two major components. The first component is USDA's "GAPs Grower Certification Program" effected in late 2002. The grower certification is the end product of a USDA program operated in conjunction with the Federal State Inspection Service (FSIS). These two agencies created a third-party audit matrix used as an inspection guide for GAPs third-party audits performed by USDA/FSIS. People passing USDA third-party audits are named on a USDA web page as "GAPs Certified," a designation increasingly demanded by buyers of fresh produce.

While GAPs is a voluntary multiinstitutional program creating market opportunities for growers of all scale, with this new process even the smallest-scale grower can be "USDA Certified" and use such designation as a marketing tool.

The second fresh produce food safety system component arose in the FDA. It is commonly called "FDA registration" because growers and others register their operations on an FDA website and receive a grower identification number. In effect since $12 \mathrm{Dec}$. 2003 , that registration (while perhaps not intended to be so) is a functional partner of GAPs certification for risk management. This is because concepts of recall, traceback, tort liability, and due diligence are imbued in the procedures growers adopt to become GAPs certified. Once becoming certified, most then register with FDA because they see the utility of having a grower identification number. Growers adopting GAPs (the first component) and finding it helpful rather than harmful increasingly see no reason not to become FDA registered, too.

By developing new GAPs programs to fit the specific needs of the packing and chain store operations in the southeastern U.S., the team expects to reduce the possibility of illness originating from southeastern fresh fruit and vegetables. The successful implementation of GAPs programs by southern produce facilities will strengthen the existing food security framework and will serve as a valuable training tool for fresh produce industries nationwide.

\section{Conclusion}

This project trained stakeholders to be their own change agents as they respond to unintended consequences of concerns about food safety. This project's new user-developed agricultural risk management curricula, materials, and self-assistance systems will help preserve conventional, sustainable, small-scale, minority- and women-owned fresh produce farming systems in all states.

A fresh-produce food security network of 12 land grant institutions is in place, containing a representative from each food science and horticulture department in the region; more than 300 specialized cooperative extension agents were trained in new food security considerations; 34 guiding publications were created and 20,000 people have adopted GAPs and are implementing them as real security for the food system in the U.S.

\section{Literature cited}

Maslow, A. (1943). A theory of human motivation. Psychological Rev. 50:370-396.

Osborne, D.J., D.C. Sanders, D.R. Ward, and J.W. Rushing. 2005. Securing the food chain: The 2000-2004 southeastern U.S. fresh produce food safety train-the-trainer program. HortTechnology 15:875-879.

Osborne, D.J., D.C. Sanders, J. Rushing, and D.R. Ward. 2003. A model recall program for the fresh produce industry. J. Assn. Food Drug Officials 67:6-25.

Osborne D.J., D.C. Sanders, and D.R. Ward (eds.). 2001. Program materials for southeastern fresh produce food safety training program, a training manual. USDA-CREES Project No. 00-511109722. Natl. Integrated Food Safety Initiative. Dept. of Horticultural Science, North Carolina State Univ., Raleigh.

Rogers, E.M. 1995. Diffusion of innovations, 4th ed. Free Press, New York.

Rushing, J.W. 2001. A case study of salmonellosis related to the consumption of fresh-market tomatoes and the development of a HACCP program. HortScience 36:29-32.

U.S. Food and Drug Administration. 1998. Guide to minimize microbial food safety hazards for fresh fruits and vegetables. Food Safety Initiative Staff HFS-32. U.S. Food and Drug Administration, Washington, D.C. 